\title{
Research Paper: Assessment of Tourism Development Compliant with Ecotourism Principles, Case Study: Guilan, Iran
}

\author{
Mehdi Hesam $^{1 *}$, Fatemeh Bagheri' ${ }^{1}$, Arash Atefi ${ }^{2}$ \\ 1. Assistant professor, Faculty of Literature and Humanities, University of Guilan, Iran. \\ 2. Department of Urban Design, Faculty of Arts and Architecture, University of Guilan, Iran.
}

Article info:

Received: 08 Nov. 2019

Accepted: 21 May 2020

Keywords:

tourism development, ecotourism principles, barometer of ecotourism, Guilan
Citation: Hesam, M., Bagheri, F., \& Atefi, A. (2020). Assessment of Tourism Development Compliant with Ecotourism Principles, Case Study: Guilan, Iran. Journal of Sustainable Rural Development, 4(2), 263-276. https://doi.org/10.32598/ JSRD.4.2.12

https://doi.org/10.32598/JSRD.4.2.12

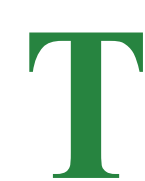

\section{Introduction}

he tourism industry, with significant positive and negative effects on the national

\section{A B STRACT}

Purpose: The purpose of the present research is to evaluate the compliance of tourism development with the ecotourism principles based on the opinions of visitors of Guilan province as a unique destination in Iran.

Methods: This study was conducted using the descriptive-analytical method. A questionnaire was designed and then filled by the visitors. The gathered data were analyzed by binomial, Friedman, and path analysis in SPSS and LISREL software. The barometer of ecotourism was also modified to explain human welfare and natural ecotourism.

Results: The results of this research indicated that the tourism activities are significantly compliant with the ecotourism principles and that education and awareness can considerably influence other dimensions.

Conclusion: Tourists in the study area are highly interested in observing the principles of ecotourism. This is seen in all aspects of helping the local economy, protecting the environment, communicating with the local community, and education. Besides, the status of environmental protection is appropriate in the study area. This is likely resulted from the understanding of the visitors about the unique nature of Guilan province and its outstanding features. The scarcity of these resources has made tourists more protective of them. On the other hand, since most of the tourists in this province have recreational purposes, more attention should be paid to education as one of the pillars of ecotourism.

* Corresponding Author:

Mehdi Hesam, PhD

Address: Faculty of Literature and Humanities, University of Guilan, Iran.

Tel: +98 (13) 33690274

E-mail: Mhesam@guilan.ac.ir 
one of the most important factors in the transformation of the new world (Cohen \& Kennedy, 2000). Development of the industry with the increasing number of tourists and their expenses - which is expected to continue in the coming years (Dwyer, 2016) - has become one of the most appealing sources of income in some countries. However, efforts should be made to avoid the market ideology that monopolizes the benefits of tourism for the socio-political elite of society (Higgins-Desbiolles, 2006) in order to increase its positive benefits for the public and local community and reduce its negative effects.

With the rapid growth of mass tourism and its negative environmental effects, the tendency has shifted towards responsible travel and ecotourism (Neto, 2003; Sriarkarin \& Lee, 2018). Ecotourism is a new and different form of nature-based travel seeking to protect local heritage and local culture by improving the well-being of the local community (Tseng et al., 2019; Cia et al., 2019; Serra, 2007). This kind of tourism has shown that it can serve as a strong force to revitalize the environment and reduce poverty in the host community (Blangy \& Mehta, 2006; Ghahroudi et al., 2012; Kry et al., 2020) and is an appropriate policy to achieve the goals of sustainable development (Anup, 2013). In order to achieve sustainability in tourism development, it is necessary to have an ecotourism approach. According to the literature, a wide variety of principles can be figured out for ecotourism. In many studies, these general principles include environmental protection, education, preservation and experience of indigenous culture and creating positive economic effects (Ankersmid \& Kelder, 2000; Cobbinah, 2015); however, in the tourism industry, this concept is often used only as a marketing method and to attract more customers as eco-tourists (Cobbinah, 2015), as its basic principles may be ignored by tourism providers and governments. Hence, it is necessary to study the ecotourism system and observe its principles by considering all elements of the tourism system. In other words, since one of the most important components of the ecotourism system is the visitors, which should have given characteristics to call it ecotourism, it is necessary to measure the consistency of their behaviors and actions with the principles of ecotourism. This can be a great practice guide for tour package designers and sustainable tourism development planners in a destination. On the other hand, regarding all the principles of ecotourism, educating the visitors and raising their awareness can play an important role in promoting their observance of the principles. In other words, creating awareness of the principles of ecotourism among the visitors is a necessary precondition for ecotourism (Chiu et al., 2013; Sorshjani, 2018; Gilbert, 2003).

Despite the importance of the role tourists play in achieving the goals and principles of sustainable tourism development, according to the literature review of the previous studies, it was found that except in a few cases, which examined tourists' perceptions of sustainable tourism destinations (Cottrell et al., 2003; Chan \& Baum, 2007; Yacob et al., 2011; Sangpikul, 2019), so far no comprehensive study has been conducted using this approach and the present study can contribute to the development of literature related to the sustainable development of tourism and ecotourism. Therefore, this article has been compiled with the aim of examining the extent to which visitors' actions conform to the principles of ecotourism. To study the issue, Iran, and in particular, Guilan province in the northern region of Iran, has been selected as one of the main destinations for ecotourism. There are no accurate and reliable statistics about the exact number of incoming tourists (domestic and foreign tourists) to this province; however, the proximity to the Grand Bazaar of Tehran, the capital of Iran, on the one hand, and the existence of attractions and abundant natural and human resources for tourism development, on the other hand, has created considerable potential for ecotourism development in this province. Therefore, the main purpose of this study is to assess the extent to which tourists adhere to the principles of ecotourism or their activities are consistent with these principles. Accordingly, the most important research questions are as follows: 1) What are the main purposes of tourism visitors to travel to Guilan province? 2) What are the components, dimensions, indicators and sub-indicators of tourism development in the form of ecotourism in the potential destinations? 3) How are the components, dimensions, indicators and sub-indicators of ecotourism perceived by the visitors to Guilan province?

In this research, an attempt is made to review the relevant theoretical literature and previous studies to answer these questions. This research aims to outline an innovative framework for assessing the compliance of visitors activities with ecotourism components and indicators in the destination of Guilan using the research approach mentioned in the following sections.

\section{Literature Review}

Today, a wide range of government policies and regulatory tools, educational approaches and local management measures of the tourism industry are attempting to regulate the relationship between tourism development 
and nature, as the ecotourism (Weaver \& Lawton, 2007). On the other hand, the degradation of the environment and natural resources, as well as the increasing pressure of urban activates on human life, have greatly affected human motivation to spend leisure time in nature and among natural attractions (Sai-Leung et al., 2010). The demand for tourism has been augmented in natural and geological environments (Hadzic et al., 2010). The term ecotourism means visiting pristine natural areas in a way that, while protecting the ecosystem, also pays attention to the dignity and respect of local communities (Ricklefs, 2001). Ecotourism is currently a very important part of the global tourism industry (Fennel, 2020) and has significant impacts upon many regional and national economies, local people and the environment (Tseng et al., 2019). There is no consensus on the definition of ecotourism in the tourism literature. However, Weaver argues that the definition of ecotourism has changed from the traditional view of "being a form of tourism" to an approach to "being in tourism" (Weaver, 2008). Therefore, it can be said that today ecotourism is one of the fastest-growing components of the green economy in the tourism industry, which emphasizes environmental protection and economic and social development (Anup et al., 2015). In other words, ecotourism is a form of postmodern tourism that is more closely related to the socio-economic structures of local communities and plays a key role in the development of rural areas by creating job opportunities and sources of income. It is a powerful instrument for the protection of biodiversity and local cultures (Inali, Jafari \& Tabire, 2014).

In the theories and perspectives concerning ecotourism, different classifications are presented of different types of ecotourists. For example, Kassler (1991) classified ecotourism into three categories: free ecotourists, organized ecotourists, and academic groups. Lindbergh (1991) offers another classification. According to the amount of time they travel, the expectations they have of the trip and the means by which they travel, Lindbergh divided the ecotourism visitors into four categories including scientific and educational researchers, individual travelers interested in conservation and culture, and the environment, the people interested in unusual exceptional journeys and those with occasional visits to attractions. In all four groups, the development of ecotourism depends on the participation and support of the local community (Pornprasit \& Rurkkhum, 2019; Yoon, Gursoy, \& Chen, 2011). In fact, the development of ecotourism cannot achieve its goals and be successful without regarding the views and support of the local community (Quezada-Sarmiento, Macas-Romero, Román and Martin, 2018). In this regard, the concept of Communi-
ty-Based Ecotourism (CBE) is a growing phenomenon in developing countries. The concept of CBE states that the communities play a key role in participating in and controlling ecotourism projects and that a significant portion of the economic benefits of tourism development remains within the community (Tosun, 2005). In the literature about the $\mathrm{CBE}$, there are three main kinds of investment including investment management by the community itself, community-based investment or creative groups, and joint ventures between the community and family with an identified foreign business partner (Wesche \& Drumm, 1993). In all the three approaches, the role of the local community must be considered in the economic benefits of ecotourism development.

Given these principles, as a general guide to direct ecotourism to the path of its existential philosophy, according to some authors (Papli Yazdi \& Saghaei, 2006; The Ecotourism International, 2015), the ecotourism has four basic characteristics: a) leaving positive effects in the field of environmental protection and improving the quality of its management; b) having the least negative impacts on the environment and local communities; c) maximizing the participation of local people in making decisions related to tourism activities; d) providing suitable opportunities for local people and tourism stakeholders to improve productivity and sustainability.

One of the comprehensive studies in this field is the work of Bossel (1999). He has presented five models for evaluating the sustainability of tourism based on indicators; 1) ecological footprint, 2) barometer of sustainability, 3) ad hoc or trial-and-error selection of indicators, 4) pressure-state-response framework, 5) system approach (Bossel, 1999). In this regard, in the study of Badri and Eftekhari (2003), regarding sustainable development, three types of evaluations have been introduced in terms of the subject: environmental evaluation, social evaluation and economic evaluation. They emphasize that these principles are not in conflict with each other and should be seen together; for example, gaining economic benefits for the local community should not cause environmental damage. More specifically, environmental protection, equity, education, and economic benefits are among the highlights of sustainable ecotourism in Powell and Ham's (2008) study. More specifically, Fennell (1999) and Blamey (2001) believe that the fundamentals of ecotourism are based on the three principles of economic, socio-cultural and environmental sustainability, which emphasize education and learning, management and nature-based journeys. 


\section{First: nature tourism}

Classic ecotourism develops only in natural areas and, of course, affects the history and culture of the affected area. These cultural elements can be considered as a subsidiary attraction in the field of ecotourism. It should be noted that ecotourism may involve an entire ecosystem as a whole or only a specific natural attraction of that ecosystem (Fennell \& Weaver, 2008).

\section{Second: Learning opportunities}

Ecotourism should create maximum satisfaction in visitors by creating opportunities for learning on site and help improve their understanding of nature and culture. At a deeper level, however, the interpretation has a profound influence on ecotourism, leading them to adhere to environmental ethics (Fennell, 1999; Orams, 1997).

Third: management; economic, socio-cultural and environmental sustainability

The most controversial part is how to manage ecotourism to result in sustainability. There is no doubt about the importance of the issue of sustainability and if ecotourism is to be considered as a prominent supreme aspect of tourism in line with sustainable development, it should be possible to measure it in different regions (Fernández, \& Sánchez Rivero, 2009). However, it is very difficult to assess sustainable development trends and its aspects. Therefore, the indicators of this assessment should be defined and the thresholds of each aspect of sustainability should be determined for this purpose (Fennell $\&$ Weaver, 2008). Measuring the sound implementation of the principles or their evaluation should be considered as one of the main goals of tourism planning. In other words, to examine the extent to which ecotourism and its principles have been observed among tourists, it seems necessary to explore the drawbacks of this approach and its changes as the goals of ecotourism evaluation. For the accurate determination of indicators and components of ecotourism, it can be helpful to study the historical trend of ecotourism. The concept of ecotourism has evolved over time. Before the $1990 \mathrm{~s}$, the concept relied only on environmental protection, and after the $2000 \mathrm{~s}$, it found a broader scope of the dimensions including education, justice, economic and social benefits, and attention to the moral dimension, responsibility and protection of indigenous culture in addition to environmental protection (Cobbinah, 2015). Selection of ecotourism destinations by visitors and the evaluation of these destinations from their perspective can be effective in understanding the compliance of the tourism system with the principles of ecotourism. The variables affecting the demand for travel to the destinations can be income, age, sex, education, interests and motivations of the visitor as well as economic, political and social status of the home countries, and also the level of access to tourism destination information (Yap \& Allen, 2011). Some other variables are travel services, advertising and media, restrictions in the destination and origin, security, the target market of tourism, rules and regulations in the origin and destination, development level of services and infrastructure, climatic conditions, use of new technologies in tourism services, number of incoming visitors in the destinations, travel expenses (Sun et al., 1991; Sunday, 1978), tangible and intangible experiences (Sun et al., 1991), lifestyle, attitude and perception (Yap \& Allen, 2011).

With these descriptions, ecotourism assessment is a tool that can help tourism decision-makers and policymakers to know what they should or should not do in an effort to build a more sustainable society. This requires the use of methods and tools for assessing the progress towards ecotourism. One of the most important tools that can measure the compliance of the visitors in an area with the principles is the barometer of ecotourism. The barometer in this study is presented with a fundamental modification of the barometer of sustainability. Indeed, different dimensions, indicators and items have been considered for the two basic components of the welfare of the human system and the natural ecosystem. According to the literature and models mentioned in previous studies, these models have been modified using an innovative approach in this study. The two models developed are ecotourism barometer and ecotourism radar.

\section{Methodology}

This is an applied research in purpose with a quantitative approach to the analysis of data. The research data have been collected through field studies with a researcher-made questionnaire. The statistical population of the study is all incoming visitors to Guilan province. The sampling method is available sampling and since there are no accurate and reliable statistics on the number of incoming tourists to the province, based on Cochran's formula and with a $95 \%$ confidence interval, the sample size has been determined 384 people. The following tests and statistical indicators have been employed to analyze the data obtained from the questionnaire:

1) Descriptive statistics such as frequency and mean have been used to describe the demographic characteristics of the statistical sample. 
2) Exploratory factor analysis has been used to group the motivations of visitors to the province.

3) The Kolmogorov-Smirnov test (K-S test) has been used to measure the normal distribution of the data and determine the parametric or non-parametric type of analysis. In this test, the impact assessment is divided into two categories and the test is performed based on these two groups. It has a significance coefficient of less than 0.05 indicating the significance of the data and the results. Due to the abnormal distribution of data, non-parametric statistical tests of Wilcoxon and Kruskal-Wallis have been used to measure the difference between the principles of ecotourism among tourists.

4) Finally, in LISREL software, path analysis has been used to measure the impact of the indicators on each other.

5) To measure each of the environmental, socio-cultural and economic dimensions of ecotourism in the ecotourism radar model, in the first stage, the studied indicators have been oriented and then the resulting quantities have been converted into relative non-scale data. To do this, the minimum and maximum amount of each indicator have been determined with the range of changes. Then, the minimum numerical value of each denominator and the obtained number has been divided by the amplitude of the fluctuations to obtain non-scale relative data between zero and one. Finally, the relative data obtained for each of the indicators in each of the three dimensions has been averaged and the obtained number has been considered as an ecotourism index in each dimension. To convert quantitative calculations into qualitative measures, the five classes of Prescott Allen presented in Table 1 have been used.

In order to calculate the status of ecotourism in the province, the ecotourism barometer has been used for the data. In the barometer, the three main indicators are the natural ecosystem, human system and motivation. The components, dimensions, indicators, sub-indices and items of ecotourism are given in Table 2.

Table 1. Prescott-Allen (1997) Five Classes for classifying ecotourism levels

\begin{tabular}{|c|c|c|}
\hline Status & Value & Rank \\
\hline Consistent with ecotourism principles & $81-100$ & 1 \\
\hline Potential ecotourism & $61-80$ & 2 \\
\hline Moderate & $41-60$ & 3 \\
\hline Weak consistency with ecotourism principles & $21-40$ & 4 \\
\hline Not consistent with ecotourism principles & $0-20$ & 5 \\
\hline
\end{tabular}

Reference: (Prescott-Allen, 1997)

Table 2. The variables of the research

\begin{tabular}{|c|c|c|}
\hline $\begin{array}{l}\text { 드 } \\
\text { 등 } \\
\text { 을 }\end{array}$ & $\begin{array}{l}\frac{c}{0} \\
\frac{c}{0} \\
\frac{\varepsilon}{0}\end{array}$ & 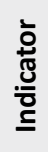 \\
\hline
\end{tabular}

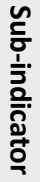

Conservation

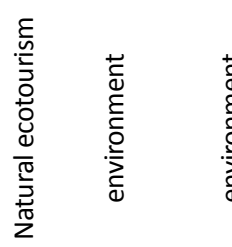

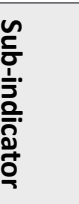

Items

Conservation through the creation of guards and the control of the entry of tourists, the protection of certain plant and animal species in the destination and control of access to them, the desire to visit protected natural areas and wildlife sanctuaries, the protection of attractions with the risk of falls and natural hazards, coordination with officials and supervisors and guards before entering a tourist destination

Taking care not to harm the pristine attractions, adapting the attractions and tourism services to the environmental conditions of the region, having a sense of responsibility for the preservation and integrity of the natural ecosystem of the region, trying not to harm the nature while visiting natural and biological resources, trying to adapt the interests and desires to the environmental conditions, desire to determine and control the access routes to different parts of a tourist place

Not leaving garbage Using less disposable items at the place of visit, avoiding using plastics, using at the destination bags, or any other tool to control garbage 
Table 2. The variables of the research

\begin{tabular}{|c|c|c|c|c|}
\hline 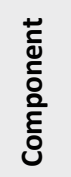 & 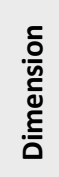 & $\begin{array}{l}\grave{0} \\
\stackrel{0}{0} \\
\text { 음 }\end{array}$ & $\begin{array}{l}n \\
\frac{n}{0} \\
\frac{1}{5} . \\
\frac{0}{\bar{n}} \\
\overline{0} \\
\underline{0} \\
\underline{0}\end{array}$ & Items \\
\hline
\end{tabular}

The virginity of tourist attractions, the health and low damage to attractions and maintaining their originality, the traditional and architectural compatibility of the known accommodation with the environment, the experience of unknown, impassable and dangerous places, not touching sensitive attractions, curiosity to discover an event or problem inside the attractions, visiting fragile virgin and remote views, understanding part of the natural and cultural history of the province

High scientific and educational value of natural attractions for learning, having the desire to teach scientific content of nature through attractions, the experience of training courses such as travel in nature, survival exercise in nature, conducting scientific research and discovering the attractions of the region, seeing various and complex phenomena and complications

Awareness before the journey

Awareness of the biological and geological attractions of the province, information and awareness about the scientific and intrinsic value of natural and cultural attractions of a place, information and awareness of historical, cultural and natural conditions before the travel

The experience of observing the appealing sites and unwillingness to see the entertainment centers, observing a tourist site from several different paths and several different perspectives, visiting them several times and each time with a different approach to a site, staring at attractions, looking at them once from a distance and through a sky view

Trying to learn the safety rules and tips from the guide and protection signs available before entering a tourist site, recording training and protection tips, obtaining the necessary information and tips from a tour leader or local guide or any other person while visiting an attraction, observing safety precautions to ensure your safety in the attractions

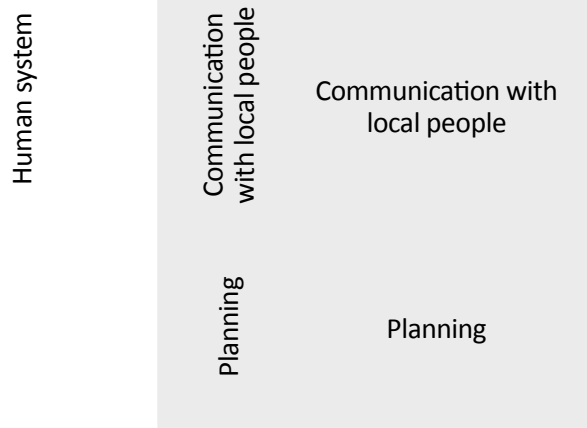

Buying handicrafts

Purchasing in local stores

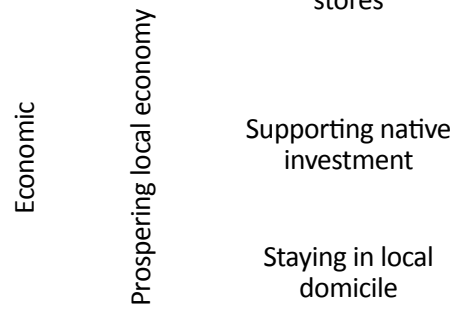

Economic profits of indigenous peoples
Willingness to learn about indigenous rituals and traditions, communicating with indigenous peoples, not offending them, living with them, living on indigenous farms and agricultural and forest environments, learning about the attraction properties through local people and local guides, acquaintance with the culture and traditions of the region in relation with local cultural and historical elements, talking to local people while visiting tourist attractions, adaptation to the new area, using tourism services, gaining experience from local places and people

Having the desire to roam independently, having the desire to travel with experienced and attraction-aware travelers, gathering information about the destination, having the desire to manage the journey by yourself instead of the tour leader, identifying destinations and tourist routes by yourself, pre-travel planning, encouraged travel agencies, the importance of the route, road or means of travel and the importance of visiting attractions

Buying handicrafts produced by locals, encouraging others to buy local products and handicrafts, trying local food and clothing and having a good memory

Purchasing from local stores to provide more essential equipment, not buying from other places or home country, buying items that are local and have local freshness and innovation, trips in the destination by local drivers and reluctance to use the agency services

Suggesting new solutions to local businesses and giving different ideas to local entrepreneurs to develop their business, having a tourism business in the province or cooperating with local entrepreneurs, having the desire to invest in tourist attraction opportunities, having the desire to do more tourism activities in the region by indigenous peoples

Accommodation preference to stay in ecotourism resorts or ecotourism hotels, preference to stay in rural houses in villages

Indigenous peoples gaining economic and social benefits to the native community, spending more on economic benefits for indigenous peoples, having the desire to provide economic benefits and income to indigenous peoples when renting accommodation or buying native tourism products instead of thinking about prices and costs 


\section{Findings}

\section{Descriptive characteristics of respondents}

The respondents to the research questions were visitors to the attractions of the Guilan province once asked to fill the questionnaires. Among the respondents, about $88.9 \%$ were less than 40 years old. Most of these people were present in various attractions of the province. Also, most of them were educated people and $42.2 \%$ of them had a master's degree. Most of the job status was related to university students with $41.1 \%$ of the sample. Due to the fact that north Iran, among all other areas of the country, has a special natural situation of dense forests and beautiful seashore, most visitors have already experienced travel to this region several times; about $70.1 \%$ of them have traveled to the region three or more times. Table 3 shows that $64.8 \%$ of the respondents have traveled to Guilan for recreation and often $(77.6 \%)$ with their family members.

Status of ecotourism dimensions

Social and cultural dimension
In the social and cultural index, there are indicators such as education, travel planning, and communication with the local community. Each of the indicators has been explored by their relevant items. Analysis of binomial test of the status of these indicators and items shows that regarding the planning indicator, $95 \%$ of the respondents are reluctant to have a journey with a determined plan and are more interested in having flexible time and travel plans. Regarding the question related to the desire to have a tour guide, $98 \%$ stated that they feel free to manage the journey themselves and identify the attractions and travel routes. As a result, 83\% said that travel agencies had played no role in planning or managing their travel. However, $82 \%$ admitted that although they would like to manage their travel time by themselves, they would like to have someone familiar with the attractions as a companion. Due to this interest in scheduling their travel, about $81 \%$ of the respondents had already gathered the necessary information about their destinations. The results of the Friedman test of the planning dimension also show that the highest planning item is related to the interest in having an informed and experienced companion, with an average of 4.24 , and the lowest is related to the item of travel management by a tour leader, with an average of 1.63 .

Table 3. Descriptive statistics of the respondents

\begin{tabular}{|c|c|}
\hline Variable & Descriptive statistics \\
\hline Age & $\begin{array}{l}\text { About } 6.2 \% \text { of the respondents were less than } 20 \text { years old, } 49.7 \% \text { between } 20 \text { to } 30 \text { years, } 33 \% \text { from } 30 \text { to } 40 \text { years, } \\
\qquad 8 \% \text { from } 40 \text { to } 50 \text { years and } 3.1 \% \text { more than } 50 \text { years. }\end{array}$ \\
\hline Gender & More than $44.8 \%$ of the respondents were male and $52.2 \%$ were female \\
\hline Education & $\begin{array}{c}\text { About 3.1\% of the respondents had no academic degree, } 9.1 \% \text { had an undergraduate degree, } 37.5 \% \text { had a bachelor's } \\
\text { degree, } 42.2 \% \text { had a master's degree, and } 7.8 \% \text { had a PhD and higher }\end{array}$ \\
\hline Employment & $\begin{array}{l}\text { About } 13.3 \% \text { of the respondents were in search for a job, } 20.3 \% \text { were students, } 41.1 \% \text { were self-employed, } 18.8 \% \\
\text { were employed in governmental organizations, } 5.7 \% \text { were housewives, and about } 0.8 \% \text { had other occupations. }\end{array}$ \\
\hline $\begin{array}{l}\text { Economic } \\
\text { situation }\end{array}$ & $\begin{array}{l}\text { About } 7 \% \text { of the respondents were relatively poor, } 84.1 \% \text { were medium, } 8.1 \% \text { were rich families, and } 0.5 \% \text { were very } \\
\text { rich families. }\end{array}$ \\
\hline $\begin{array}{l}\text { History of } \\
\text { travel to the } \\
\text { province }\end{array}$ & $\begin{array}{l}\text { About } 6.8 \% \text { of the respondents had experienced no travel to the region, } 9.9 \% \text { had traveled once, } 13.3 \% \text { had traveled } \\
\text { twice, and } 70.1 \% \text { had traveled three times and more }\end{array}$ \\
\hline $\begin{array}{l}\text { Form of } \\
\text { travel }\end{array}$ & $\begin{array}{c}\text { About } 2.9 \% \text { of the respondents had traveled via tour, } 77.6 \% \text { by family, } 11.2 \% \text { individually, } 1.8 \% \text { by camping, and } 6.2 \% \\
\text { by other ways }\end{array}$ \\
\hline $\begin{array}{l}\text { Travel moti- } \\
\text { vation }\end{array}$ & $\begin{array}{l}\text { About } 64.8 \% \text { of the respondents had come for recreation, } 1.8 \% \text { for research, } 1.3 \% \text { for transit, } 15.4 \% \text { for visiting rela- } \\
\text { tives, } 1.6 \% \text { for work, } 5.2 \% \text { for understanding nature and communicating with the region, and } 0.8 \% \text { for other purposes }\end{array}$ \\
\hline $\begin{array}{c}\text { Type of } \\
\text { accommoda- } \\
\text { tion }\end{array}$ & $\begin{array}{l}\text { About } 11.7 \% \text { of the respondents had stayed in hotels, } 24.7 \% \text { in hostels and resting houses, } 21.9 \% \text { in ecotourism ac- } \\
\text { commodations, } 17.4 \% \text { in tents, } 23.2 \% \text { in relatives' houses, and } 0.3 \% \text { in other places. }\end{array}$ \\
\hline
\end{tabular}


In the field of education, $45 \%$ responded that the scientific and educational value of attractions is not important to them and scored it below average. As mentioned in the descriptive statistics, $64.8 \%$ of the visitors had a recreational motivation, which is consistent with these results. As a result, 59\% stated that they do not have adequate knowledge about the natural and geological attractions of Guilan province. However, $64 \%$ of the respondents admitted that although they do not have enough knowledge about many attractions, they want to get acquainted with the scientific content of tourism and nature during the travel. About $75 \%$ are also interested in learning about travel rules and gaining experience. The results of the Friedman test in terms of education also show that the highest value is related to the item of knowledge about sensitive and fragile natural and human attractions with the don't-touch warning, with an average of 4.68 , and the lowest, with the average of 3.38 , is also related to the item of familiarity with natural and geological attractions of the province.

In terms of communication with the local community, $85 \%$ of the visitors responded that they would like to get acquainted with the public traditions and norms and have interactions with local people. Also, $88 \%$ said that they try not to offend the local people. Therefore, this item has the highest rank in the Friedman test with an average of 4.6 . About $77 \%$ of the visitors felt the need to use local guide services. Although, the item of enduring hardship due to gaining new travel experience with an average of 3.69 has got the lowest value.

Regarding the local economic aid, $89 \%$ of the visitors like to buy local handicrafts or encourage others to buy them. Also, $89 \%$ of them prefer to buy their needed items for travel in the destination. According to the Friedman test, the purchase of handicrafts with an average rating of 3.21 is the highest item and supporting the economic profit of indigenous people with an average rating of 2.8 is the lowest indicator.

\section{Environmental dimension}

Regarding the environmental index, most of the visitors believe in the protection of the environment by government environmental guards and determined protected areas. Also, $98 \%$ of them are cautious not to harm the environment during their journey and $94 \%$ also avoid throwing garbage in the nature. Hence, according to the Friedman test, the item of not-harming the environment with an average value of 8.69 is the highest and the item of respecting environmental officials and guards with an average rating of 4.77 is the lowest in this dimension.

\section{Economic dimension}

Regarding the economic dimension, according to the Friedman test, the best situation is related to the fact that the local community must gain the economic benefits from the visitors, which is in the first place with an average rank of 10.04. In this item, based on a binomial test, $83 \%$ of the respondents strongly believed that the economic benefits should be delivered to the local community. Nevertheless, the lowest value of this dimension is related to the willingness of the visitors to pay more costs as economic benefits to local people with an average rank of 6.32. But in general, based on the binomial test, $95 \%$ of the visitors tend to help the local economy during their stay in Guilan province. This can be considered as a good capacity for ecotourism.

\section{Prioritization of ecotourism dimensions}

According to the economic, socio-cultural and environmental dimensions of ecotourism, the degree of compliance of these principles in terms of incoming tourists to the area can be seen in Figure 1. The results show that the environmental dimension of ecotourism with a score of 0.83 is the highest among other dimensions. Following the environmental dimension, the next is the economic dimension with a score of 0.76 and then the socio-cultural with a score of 0.7 as the second and third. These results indicate that the importance of maintaining environmental health is a higher priority for tourists, and of course, in order to proceed in complying with this principle, it is essential to develop relevant necessary infrastructures such as the existence of garbage bins or camping facilities.

In general, based on the results of the ecotourism barometer in Figure 2, the tourism situation in Guilan province is assessed as "fair or almost sustainable" in accordance with the principles. According to the respondents, the natural ecosystem, with a score of 0.83 , has been evaluated better than the human system, with a score of 0.71 .

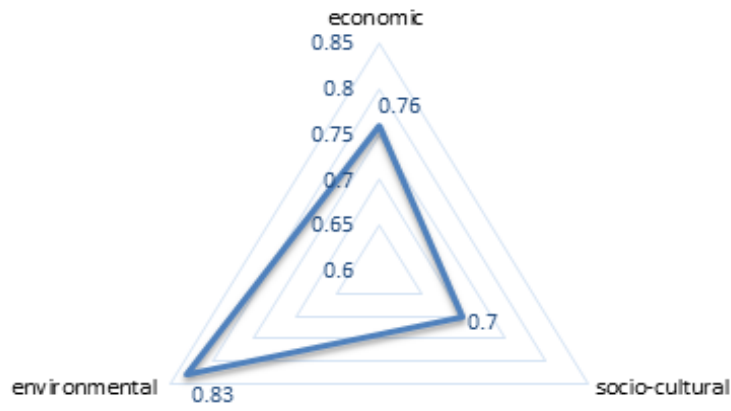

Figure 1. Ecotourism dimensions radar 
But the ecotourism radar diagram in Figure 3 shows that travel planning has the lowest status among other indicators and the highest value is related to the environmental dimension of ecotourism in Guilan province.

Finally, the results of path analysis (Figure 4) in LISREL software also indicate that the education and aware- ness of visitors have a great impact on the communication with the local community $(0.71)$, helping the local economy (0.74) and environmental protection (0.7). However, the influence of the awareness indicator on the travel planning index is not significant in the results (Figure 5)

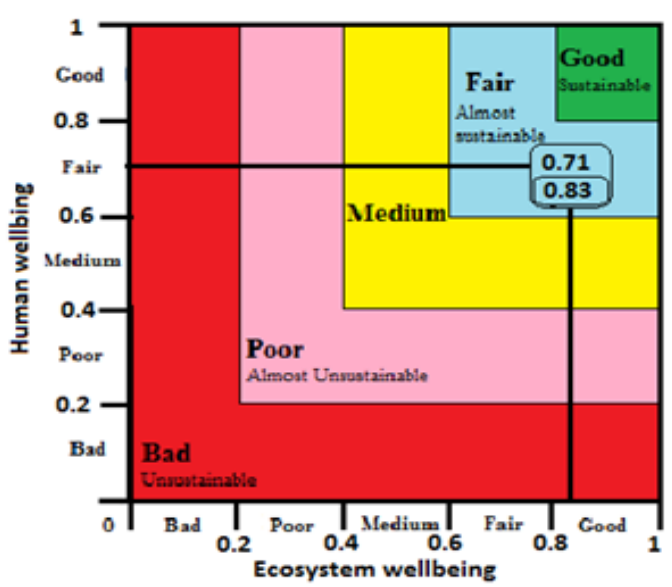

Figure 2. Barometer of ecotourism

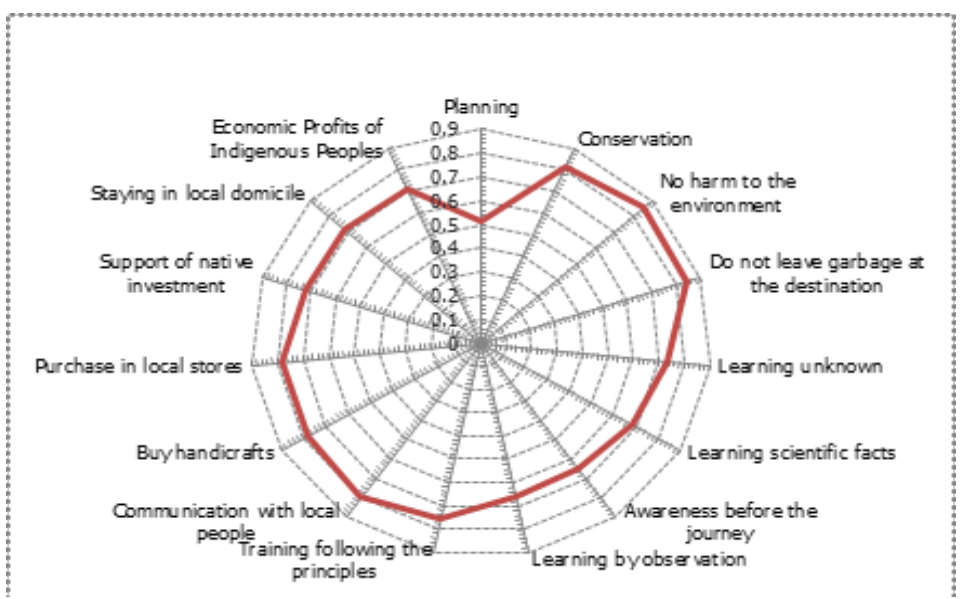

Figure 3. Radar of ecotourism sub-indicators

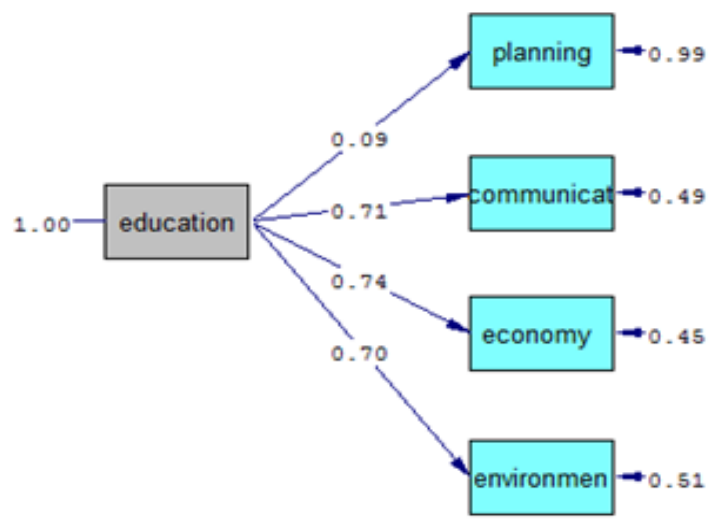

Figure 4. Path analysis of the impact of education and awareness on the dimensions of ecotourism 
According to the research results and Friedman's test, "recreation and relaxation" is ranked as the highest average motivation for visitors to the area. Based on the two-ball test, $90 \%$ of the respondents chose the aboveaverage scores for recreation. Visiting geo-sites and biological places are ranked second. The geo-sites include rivers, forested hills, marine views, beaches, mountainous areas, etc. and biological places include animal and vegetation species with Caspian and Hyrcanian forests in the three Northern provinces of Guilan, Mazandaran and Golestan. The lowest rank is related to economic motivation such as shopping, business or employment. Due to the outstanding natural conditions of the region, most visitors were motivated to have fun in nature. Therefore, this effect of education can play a significant role in enhancing the ecotourism characteristics of the guests.

Based on the exploratory factor analysis test, the Bartlett test and KMO index have been used in order to assess the appropriateness of the data associated with the set of variables for analysis of ecotourism conditions of tourists in Guilan province. According to the data in Table 4, the significance of the Bartlett test at the confidence level of $99 \%$ and the appropriate value of $\mathrm{KMO}$ (0.899) indicate the correlation and appropriateness of the variables for factor analysis.

In the following, the studied variables have been factorized through factor analysis in SPSS. The analysis reduced 74 variables to 7 significant factors (Table 5).
The first factor alone is able to explain $11.06 \%$ of the variance. It includes 16 variables and the most important are the desire to perform more tourism activities in the region by indigenous people, the experience of living with them, and the interest in getting acquainted with indigenous rituals and traditions. Therefore, the most important issues regarding the first factor is the communication with local people.

The second factor explaining $10.61 \%$ of variance includes 16 variables, the most important of which are the attempt to avoid being harmed while visiting natural and biological resources, having a sense of responsibility for protecting the natural ecosystem of the region, and not touching sensitive naturally and historically fragile attractions. Most of the load variables in this factor are associated with the environmental dimension.

In the third factor explaining variance of 10.10, 21 factors are included. The most important variables are protection via the creation of guards and controlling the entry of visitors, understanding part of the natural and cultural history of the province, and the desire to teach scientific tourism and nature through attractions. Therefore, most of the variables are related to the education and awareness of tourists.

Table 4. KMO and Bartlett's Test

\begin{tabular}{|c|c|c|}
\hline \multicolumn{2}{|c|}{ Kaiser-Meyer-Olkin Measure of Sampling Adequacy. } & .899 \\
\hline \multirow[t]{3}{*}{ Bartlett's Test of Sphericity } & Approx. Chi-Square & 1.035E4 \\
\hline & df & 2701 \\
\hline & Sig. & .000 \\
\hline
\end{tabular}

JSRD

Table 5. Total Variance Explained

\begin{tabular}{ccccccc}
\hline \multirow{2}{*}{ Component } & \multicolumn{2}{c}{ Extraction Sums of Squared Loadings } & \multicolumn{3}{c}{ Rotation Sums of Squared Loadings } \\
\cline { 2 - 7 } & Total & \% of Variance & Cumulative \% & Total & \% of Variance & Cumulative \% \\
\hline 1 & 19.047 & 25.739 & 25.739 & 8.185 & 11.061 & 11.061 \\
2 & 5.238 & 7.078 & 32.817 & 7.853 & 10.612 & 21.673 \\
3 & 3.231 & 4.366 & 37.183 & 7.410 & 10.014 & 31.687 \\
\hline 4 & 2.829 & 3.822 & 41.006 & 4.596 & 6.211 & 37.898 \\
\hline 5 & 2.148 & 2.903 & 43.908 & 2.954 & 3.992 & 41.890 \\
6 & 1.893 & 2.558 & 46.467 & 2.585 & 3.493 & 45.383 \\
\hline 7 & 1.718 & 2.322 & 48.789 & 2.520 & 3.406 & 48.789 \\
\hline
\end{tabular}


The fourth factor explaining $6.21 \%$ of variance includes 11 variables of the study. The most important of the variables in the factor are the desire to have flexible travel planning during the journey, experiencing visiting unknown places, tackling difficulties with dangerous and wonderful routes, and enjoying visiting the attractions. This factor is also mainly concerned with the variables related to the interest in learning.

Up to $3.99 \%$ of the variance can be explained by the fifth factor. The most important variables are the desire to visit the attractions, keeping safe and not damaging the unfamiliar attractions and maintaining their originality, seeing a tourism landscape from several different routes and from several different views, the experience of visiting tourist attractions and not visiting other entertainment centers, and looking at each attraction at least once from a distance and from top view. Therefore, in this factor, most of the variables are related to observation and learning via observation.

Three variables are included in the sixth factor explaining $3.49 \%$ of the variance. The variables are the tendency to develop local investors, the desire for local people to perform more tourism activities in the region, and the adaptation of attractions and tourism services to the cultural circumstances of the native community. Therefore, this factor contains the variables related to helping the local economy.

In the seventh factor explaining $3.4 \%$ of the variance, 3 factors are included. The variables are the desire to manage travel by themselves instead of using tour leader services, planning before beginning the journey, and awareness of the scientific and intrinsic value of natural attractions, and cultural places of tourism. This factor mainly includes variables related to planning.

\section{Discussion}

In this study, four indicators of ecotourism including environmental protection, prospering the local economy, education and awareness, and communication with the local community have been examined in the form of two components of the human system and the natural system. These dimensions have also been analyzed in the studies of Weaver and Lawton (2007), Higham and Lück (2002), Okech (2009) and Cobbinah (2015). Environmental protection has been considered a key indicator of ecotourism development in many studies (Tseng et al, 2019). Although Sharply (2009) believes that tourism is essentially an environmental activity; however, ecotourism due to the nature of this form of tourism develop- ment emphasizes further the importance of the environment. Without regarding environmental considerations, the term ecotourism basically does not make sense. On the other hand, if the principles of ecotourism are fully observed and implemented, it can provide adequate financial resources to protect and even revitalize and improve the quality of the environment (Blangy \& Mehta, 2006). Blangy and Mehta (2006) argued that ecological restoration plays a very important role in the development of ecotourism. However, in order to preserve the environment, in addition to the active participation of visitors just as one component of a complex tourism system, it is necessary to regard other conditions. In the present study, $83 \%$ of visitors consider environmental protection as their main concern. Nevertheless, it can be observed that this is not the case in practice, and a lot of garbage has been left in nature and the branches of many trees are broken to make fire for recreation and cooking in nature. It can be said that the main reason for many of these behaviors can be the weakness in other components of the tourism system, i.e., in the management, infrastructure and poor tourism equipment of the country. As the findings of Tseng et al. (2019) show, it can also be stated that cleanliness management and facility management are among the key factors affecting the development of ecotourism and its potential evaluation in the area. Lack of garbage bins in tourist destinations of Guilan province is one of the main problems. There are many defects in the waste collection and separation system of this province and in some cases, the wastes are also stored in nature and the surrounding environment. There are no special and equipped places as tourist camps in nature, and this can increase the potential that tourism may harm nature. Therefore, in order to achieve the principles of ecotourism, it is necessary to perform the correct operation of all elements of the supply and demand in the tourism development system.

Another key aspect of ecotourism is the discourse of its economic benefits. Many studies have demonstrated that ecotourism plays a very important role in prospering the local economy, raising living standards and promoting human development in the local communities. According to the present study, $76 \%$ of the visitors wanted to help the local economy in their travels. This should be an opportunity for the people and local businesses to develop their activities in the tourism sector. In the development of ecotourism, it should be noted that the main issues of economic sustainability include economic benefits, diversification of the local economy, controlled economic growth, improvement of local and regional relations and equal distribution of economic benefits in the local economy (Chamberlain, 2002). Community-Based 
Ecotourism (CBET) also emphasizes the fact that the local people should gain the economic benefits of ecotourism (Kry et al., 2020). According to the results, the livelihood of local people has been increased by $15 \%$ thanks to CBET average total score in the Kampong Phluk community. Regarding the socio-cultural dimension, it should be said that $70 \%$ of the visitors in the present study liked to have an interaction with local communities. According to the principles of ecotourism, these relations have to be controlled to avoid offending the local people and their culture. Up to $88 \%$ of the visitors to Guilan province admit that it is very important for them to behave in a way that does not offend the local people and their culture. However, having the right relationship with the local community, in addition to the commitment and responsible behavior of tourists, requires the attention of planning officials and planners. According to the findings of Adom (2019), whenever the culture and traditions of local people as an agent of preserving the environment are disregarded in tourism development programs, local people will be reluctant to be actively involved in ecotourism activities. This can even negatively affect their income from tourism development.

In all environmental, economic and socio-cultural aspects of ecotourism development, it is very important to pay special attention to the role of education. Based on the results of this research, education could affect the factors of communication with the local community (0.71), prospering the local economy $(0.74)$, and environmental protection $(0.7)$. The importance of the education factor has also been confirmed in Orams (1997). However, the educational content should be presented in different direct and indirect ways as well as using new communication tools in order to make it more efficient. The activities of NGOs in this field to provide oral training through tourism activists in Guilan province can be a good example. In all these cases, factors such as gender and tourist income as mediating variables can be influential. In this study, based on the Human-Whitney test, similar to the results of Moons, De Pelsmacker and Barbarossa (2020), a relationship has been found between gender and the desire to protect the environment. It can be discussed that women are more sensitive to environmental protection.

In general, it has been observed that all components, dimensions, indicators and sub-indicators of ecotourism can be categorized into two major parts, namely the natural system and the human system. The natural system means that the ecotourism activities have to minimize the detrimental effects on the environment and preserve it for future generations according to the principle of sus- tainable development; however, this does not mean that nature should be kept intact. In fact, human welfare must be ensured in accordance with the principles of respect for the environment and non-violation of the principles of sustainability. Human welfare in tourism means wellbeing for both host and local communities. This has been examined in the views of the visitors in the present study. From the tourists' point of view, the human system is evaluated 0.71 in importance and the natural ecosystem about 0.83 . Therefore, it can be argued that Guilan is relatively sustainable in terms of tourism.

Finally, it must be acknowledged that there is no perfect research without any possible critiques. This study would have been improved if the authors had been able to create a categorization of the statistical population based on the motivation of the visitors and, then, to conduct sampling from within these categories to obtain more accurate and detailed results. Also, since the present study has been conducted at the time of Covid19, this pandemic disturbed the data collection survey and made it difficult for researchers to conduct the survey.

\section{Acknowledgements}

This research did not receive any specific grant from funding agencies in the public, commercial, or not-forprofit sectors.

\section{Conflict of Interest}

The authors declared no conflicts of interest.

\section{References}

Adom, D. (2019). The place and voice of local people, culture, and traditions: A catalyst for ecotourism development in rural communities in Ghana. Scientific African, 6, e00184.

Ankersmid, P. \& Kelders, L. (2000). Lang leve Manuel Antonio en Texel. Master's Thesis, Unpublished document, Recreation and Tourism Chair Group, Wageningen University, The Netherlands.

Anup K.C., Kedar Rijal \& Ramesh Prasad, S. (2015). Role of ecotourism in environmental conservation and socioeconomic development in Annapurna conservation area, Nepal. International Journal of Sustainable Development \& World Ecology, 22 (3): 251-258.

Anup, K. C. (2016). Ecotourism and Its Role in Sustainable Development of Nepal, Tourism - From Empirical Research Towards Practical Application edited by Leszek Butowski 31-57. Publisher: InTech. 
attractions using linguistic preferences. Journal of Cleaner Production

Azam, M., Alam, M. M., \& Hafeez, M. H. (2018). Effect of tourism on environmental pollution: Further evidence from Malaysia, Singapore and Thailand. Journal of cleaner production, 190, 330-338.

Badri, S. A., \& Eftekhari, R. (2003). Sustainability assessment: concepts and methods. Journal of Geographical Research, 18(69), 9-34

Beladi, H., Chao, C. C., Hazari, B. R., \& Laffargue, J. P. (2009). Tourism and the environment. Resource and energy economics, 31(1), 39-49.

Bith, B. (2011). Community-based ecotourism and empowerment of indigenous people: the case of Yeak Laom community development, Cambodia, p.p 42- 52.

Blamey, R. (2001). Principles of ecotourism. In D. Weaver (ed.) The Encyclopedia of Ecotourism (pp. 5-22). Wallingford: CABI

Blangy, S., \& Mehta, H. (2006). Ecotourism and ecological restoration. Journal for Nature Conservation. 14. 233-236. 10.1016/j.jnc.2006.05.009

Bossel, H. (1999). Indicators for sustainable development: theory, method, applications (p. 138). Winnipeg: International Institute for Sustainable Development.

Buckley, R., Cater, C., Linsheng, Z., \& Chen, T. (2008). Shengtai luyou: Cross-cultural comparison in ecotourism. Annals of Tourism Research, 35(4), 945-968.

Butler, R. W. (2000). Tourism and the environment: A geographical perspective. Tourism Geographies, 2(3), 337-358.

Chamberlain, K. (2002). Asia pacific. In A. Lockwook A \& C. Medlik (Eds), Tourism \& hospitality in the 21st century (pp. 134-53), Buston, M.A. Butherworth Heinemann.

Chan, J, Baum, T. (2007). Ecotourists' perception of ecotourism experience in Lower Kinabatangan, Sabah, Malaysia. Journal of Sustainable Tourism 15(5): 574-590.

Chiu, Y. H. Wan-I, L. \& Tsung-Hsiung, C. (2013). Environmentally Responsible Behavior in Ecotourism: Exploring the Role of Destination Image and Value Perceptionll. Asia Pacific Journal of Tourism Research. 2013 http://dx. doi. org/10, 1080/10941665. 2013. 818048, 1-30.

Cobbinah, P. B. (2015). Contextualizing the meaning of ecotourism, Tourism Management Perspectives, 16, 179-189.

Cohen, R., \& Kennedy, P. (2000). Global sociology. Houndsmills, Basingstoke, UK: Macmillan Press.

Cottrell, S., Duim, R. V. D., Ankersmid, P. \& Kelder, L. (2009). Measuring Sustainability of Tourism in Manuel Antonio/ Quepos and Texel: A Tourist Perspective, Journal of sustainable tourism, 5, 12. 409-431.

Dwyer, L. (2016). Planning for Sustainable Tourism: An Alternative Paradigm, International Journal of Tourism and Spirituality, 1(1): 28-43

Einali, J., Jafari, G., Tabire, I. (2014). An Assessment of the Role of Ecotourism on the Development of Rural Areas (Case Study:
Uraman-e-Takht, Sarvabad). Journal of Tourism Planning and Development, 3(9), 191-211.

Fennel, D. A. (2020). Eotourism. International Encyclopedia of Human Geography, 2nd edition, Volume 4, 51-55.

Fennell, D. (1999). Ecotourism: An Introduction. New York: Routledge.

Fennell, D., \& Weaver, D. (2005). The Ecotourium Concept and Tourism-Conservation Symbiosis, Journal of Sustainable Tourism, 13:4, 373-390.

Fernández, J. I. P., \& Sánchez Rivero, M. (2009). Measuring tourism sustainability: Proposal for a composite index. Tourism Economics, 15(2), 277-296.

Ghahroudi Tali, M., Sadough, S. H., Nezammahalleh, M. A., \& Nezammahalleh, S. K. (2012). Multi-criteria evaluation to select sites for ecotourism facilities: a case study Miankaleh Peninsula. Anatolia, 23(3), 373-394.

Gilbert, R. (2003). Ecotourism and education for sustainability: A critical approach. International Review for Environmental Strategies, 4(1), 75-83.

Hadzic, O \& Markovi, S \& Vasiljevic, D \& Nedeljkovic, M. (2010). A dynamical model for assessing tourism market attractiveness of a geosite; GEOTRENDS, pp 23-25.

Hawkins, D. E. (2004). A protected areas ecotourism competitive cluster approach to catalyse biodiversity conservation and economic growth in Bulgaria, Journal of Sustainable Tourism, Vol 12, No 3, Pp 219-244.

Higgins-Desbiolles, F. (2006). More than an "industry": The forgotten power of tourism as a social force. Tourism Management, 27(6), 1192-1208.

Higham, J., \& Lück, M. (2002). Urban ecotourism: a contradiction in terms?. Journal of ecotourism, 1(1), 36-51.

Hvenegaard, C. (1994). Ecotourism, the journal of tourism studies, vol 15. No 2 .

Khanal, B., \& Babar, J. (2007). Community-based ecotourism for sustainable tourism development in the Mekong Region Bangkok, Thailand: SDC Swiss Agency for Development and Cooperation.

Kry, S., Sasaki, N., Datta, A., Abe, I., Ken, S., \& Tsusaka, T. W. (2020). Assessment of the changing levels of livelihood assets in the Kampong Phluk community with implications for community-based ecotourism. Tourism Management Perspectives. 34. 100664. 10.1016/j.tmp.2020.100664.

Kusler, J. A. (1991). Ecotourism and resource conservation: Introduction to issues. Ecotourism and resource conservation: A collection of papers, 1, 2-89.

Lindberg, K. (1991). Policies for maximizing nature tourism's ecological and economic benefits (pp. 20-21). Washington, DC: World Resources Institute.

Ma, B., Cai, Z., Zheng, J., \& Wen, Y. (2019). Conservation, ecotourism, poverty, and income inequality - A case study of nature reserves in Qinling, China. World Development, 115, 236-244.

Moons, I., De Pelsmacker, P., \& Barbarossa, C. (2020). Do personality and self-congruity matter for the willingness to pay 
more for ecotourism? An empirical study in Flanders, Belgium. Journal of Cleaner Production, 122866.

Murphy, P.E. \& Murphy, A.E. (2004). Strategic management for tourism communities: Bridging the gaps. Clevedon, Aspects of Tourism SeriesChannel view Publications.

Neto, F. (2003). A New Approach to Sustainable Tourism Development: Moving Beyond Environmental Protection, DESA Discussion Paper, No. 29.

Okech, R. N. (2009). Developing urban ecotourism in Kenyan cities: A sustainable approach. Journal of Ecology and the Natural Environment, 1(1), 001-006.

Orams, M. (1997). the effectiveness of environmental education Can we turn tourists into 'greenies'? Progress in Tourism and Hospitality Research 3, 295-306.

Pornprasit, P., \& Rurkkhum, S. (2019). Performance evaluation of community-based ecotourism: A case study in Satun province, Thailand. Journal of Ecotourism, 18, 42-59.

Powell, R.B., Ham, S.H. (2008). Can Eco-tourism Interpretation Really Lead to Pro- Conservation Knowledge, Attitudes and Behavior? Evidence from the Galapagos Islands. Journal of Sustainable Tourism, 16, 4, 2008, 467-489, ISSN 1747-7646.

Prescott-Allen, R. (1997). Barometer of Sustainability: Measuring and communicating wellbeing and sustainable development. IUCN, Gland, $\mathrm{CH}$.

Quezada-Sarmiento, P.A., Macas-Romero, J.D., Román, C., \& Martin, J.C. (2018). A body of knowledge representation model of ecotourism products in southeastern Ecuador. Heliyon, 4 .

Ricklefs, Robert E. (2001). "The Economy of Nature”, fifth edition. W. H. Freeman and Company, New York

Sai-leung, N. G \& Jiangfeng, L. I \& Shiming, F \& Young C.Y. NG. (2010). geodiversity and geoconservation in hong kong; Asian Geographer 27 (1 -2), pp 1-11

Sangpikul, A. (2019). Tourist perceptions of guided ecotourism tours in Thailand. Tourism and Hospitality Research, 20, 2: 245-256

Serra, G. (2007). Ecotourism in the PALMYRA Desert, SYRIA A Feasibility Study.

Sharply, R. (2009). Tourism Development and the Environment: Beyond Sustainability? London: Earth scan.

Sorshjani, R. H., Bidgoli, R. D., Asheri, A., \& Azad, E. R. (2018) The Effect of Ecotourism Education and Promotion to Environmental Protection (Case study: Education of Female Students in District 18 of Tehran). Sustainable Development, 6(3) 61-78.

Sriarkarin, S., \& Lee, C. H. (2018). Integrating multiple attributes for sustainable development in a national park. Tourism Management Perspectives, 28, 113-125.

Sun, S. P., Uysal, M., McLallen, R. (1991). A linear expenditure model for tourism demand. Annals of Tourism Research, Vol. 18, pp. 443-454.

Sunday, A. (1978). Foreign travel and tourism prices and demand; Annals of tourism research, April/June 1978.
Tang, Z. (2015). An integrated approach to evaluating the coupling coordination between tourism and - the environment. Tourism Management, 46, 11-19.

TIES. (The International Ecotourism Society). (2015). The definition (Online), Available: http;//www.ecotourism.org/whatis-ecotourism

Tosun, C. (2005). Stages in the emergence of a participatory Tourism-development approach in the developing world Geoforum, 36, 333-352

Tseng, M., Lin, C., Lin, C. R., Kuo-Jui Wu, K. \& Sriphon, T. (2019). Ecotourism development in Thailand: community participation leads to the value of

Weaver, D. (2001). the Encyclopedia of Ecotourism. Oxford: $\mathrm{CAB}$ International

Weaver, D. B., \& Lawton, L. J. (2007). Twenty years on: The state of contemporary ecotourism research. Tourism Management, 28(5), 1168-1179.

Weaver, D.B. (2008). Ecotourism, Milton. Queensland: Wiley Australia.

Wesche, R., \& Drumm, A. (1993). Defending the rain forest, Accion Amazonia, Quito, Ecuador.

Wood, M. E. (2002). Ecotourism: Principles, practices and policies for sustainability. UNEP.

Yacob, R. M., Radam, A., \& Samdin, Z. (2011). Tourists Perception and Opinion towards Ecotourism Development and Management in Redang Island Marine Parks, Malaysia. International Business Research, 4, 1, 62-73.

Yap, G., Allen, D. (2011). investigating other leading indicators influencing Australian domestic tourism demand; Mathematics and Computers in Simulation, 81 (2011) 1365-1374.

Yoon, Y., Gursoy, D., \& Chen, J. (2011). An investigation of the relationship betweentourism impacts and host communities' characteristics. An International Journal of Tourism and Hospitality Research, 29-44. 